Article type : Special Issue

\title{
The Resilient Organization: A Meta-analysis of the Effect of Communication on Team Diversity and Team Performance
}

\author{
Authors \\ Hong Bui*, \\ Vinh Sum Chau**, \\ Marta Degl'Innocenti***, \\ Ludovica Leone ${ }^{+}$, \\ Francesca Vicentini $^{* * *}$
}

"School of Management, University of Bath, Bath, BA2 7AY, United Kingdom. Email: H.T.Bui@bath.ac.uk.

** Kent Business School, University of Kent, Parkwood Road, Canterbury, Kent, CT2 7PE, Email: v.s.chau@kent.ac.uk .

*** Southampton Business School, University of Southampton, Highfield Southampton, SO17 1BJ, United Kingdom. Email: M.Deglinnocenti@soton.ac.uk.

+ Department of Management and Technology and Ask Research Center, Bocconi University, Via Sarfatti 25, 20136 Milan, Italy. Email: ludovica.leone@unibocconi.it

** LINK CAMPUS University, via Gregorio VII, 601, Rome, Italy. Email: f.vicentini@unilink.it This article has been accepted for publication and undergone full peer review but has not been through the copyediting, typesetting, pagination and proofreading process, which may lead to differences between this version and the Version of Record. Please cite this article as doi: 10.1111/apps.12203

This article is protected by copyright. All rights reserved. 


\begin{abstract}
The Input-Process-Output framework is adopted to examine the impact of diversity attributes (the input) on communication (the process) and their influence on performance (the outcome), to understand the internal group/team working mechanisms of organizational resilience. A meta-analysis of 174 correlations from 35 empirical studies undertaken over 35 years (1982-2017) showed that members of a team who have different experiences are more likely to share information and communicate openly when they deal with a task that requires collaboration outside the team. This supports the view that organizations are more resilient by being more closely connected with the external environment. Differences in social categories tend to favor openness of communication, especially in the case of age diversity and race/ethnicity diversity. An increase in openness of communication is likely to enhance team performance, particularly for small and medium sized teams operating in manufacturing industries, while frequency of communication can be beneficial for both large and medium sized teams working in the high technology industry. The positive workings of these associations form the resilient organization.
\end{abstract}

Keywords: organizational resilience, meta-analysis, communication, cognitive diversity, team performance.

\title{
Introduction
}

Organizational resilience has been variously defined but is generally understood as the ability of organizations to withstand shocks in the external environment, perform confidently and robustly for the long-term against business threats and remain fit for purpose (see Ortiz-Mandojana \& Bansal, 2016, for the general management overview). Hence, it involves the ability of the organization to withstand significant adversity and yet bounce back from the disturbance to perform effectively and sustainably for the future and maintain on track with its desired future in accordance with its articulated mission and strategic goals (Fleming, 2012). The phenomenon is considered most

This article is protected by copyright. All rights reserved. 
commonly in the context of overcoming natural and human disasters (eg. Tukamuhabwa et al, 2015) but has extended to broader societal contexts to relate to the business world. Its extendibility has been drawing great attention from management scholars and practitioners (eg. Carmeli \& Markman, 2011; King, Newman \& Luthans, 2016), and attempts have been made to trace its origins (eg. Ruiz-Martin et al, 2018) to understand it better. For instance, Coutu (2002) believes its roots are in human psychology, while others trace it as far back as Holling (1973) to ecology.

Over the years, the concept of organizational resilience has been studied in a number of ways: mostly as a feature of the organization, to deal with either internal or external shocks to the organization. For example, Gunasekaran et al (2011) identified the dimensions of adaptability, responsiveness, sustainability and competitiveness that comprise resilience. Lengnick-Hall and Beck (2005) are more comprehensive in suggesting three categories of resilience: cognitive (the ability to recognize adversity and respond accordingly), behavioral (the workings of the organization) and contextual (the overall framework in which the creation of resilience must operate). In a recent systematic literature review on empirical studies of organizational resilience, Barasa et al (2018) reveal that the organization is not a mere black box and that within it, organizational culture and human capital, among other factors, play important roles in the execution and creation of the organization's resilience. For example, cultures of nurturing learning opportunities and experiences help to develop capabilities that improved resilience, and improved wellbeing by better listening, stress reduction and flexible working all assist employee engagement and teamwork, and a commitment to focus on the task in mind despite any impact of crises. Ruiz-Martin et al (2018) see the wide-spread significance of organizational resilience as connected to numerous disciplines and stakeholders, and across multiple levels; this is because only resilient individuals can form resilient teams, which build resilient organizations, and resilient organizations create a resilient society.

Team resilience is still relatively emerging in the organization management literature (see for example Carmeli \& Markman, 2011; Stephens et al., 2013; West et al., 2009). As explained by West et al. (2009: p. 253) the concept of team resilience refers to the capability of teams "to bounce back from failure, setbacks, conflicts, or any other threat to wellbeing that a team may experience." 
However, it can be more difficult for teams to 'bounce back' or to overcome issues in the presence of external threat, particularly in the case of incomplete information about the environment and the presence of other team-related challenges. Under such circumstances, the communication channels and the volume of information used by team members are likely diminished (Gladstein and Reilly, 1985). This makes it more challenging for teams to coordinate activities and cooperate with oneanother, resulting in negative consequences on their performance. Resilient teams are therefore those still able to complete and reach their tasks despite such uncertainties and pressure.

Once emerging angle of organizational resilience is that within enterprise (see Verrynne et al, 2018; Manfield and Newey, 2018) - such as for small/medium sized and mostly family-run businesses, where the locus of control resides in leadership (eg. Ingram and Glod, 2018). It may be that family firms with greater team cohesion may improve awareness of environmental signals, assisting their ability to respond. Similarly, it is found that team resilience is a positive mediator between transformational leadership and team effectiveness (Dimas et al, 2018), but it is not clear how this can be operationalized. For example, in Annarelli and Nonino's (2016) review of the strategic and operational management of organizational resilience, they identify a lack of consensus on how to reach operational resilience of groups and the need to understand resilient processes better. Arguing that team resilience is not synonymous to general group and work performance resilience, Gucciardi et al (2018) present a multilevel conceptual model of team resilience in which process is key and all-embracing of individuals. They advocate the detailed understanding of organizational resilience by careful use of an input-process-output mechanism.

One of the most dominant tools adopted in the field of team or group work is in fact the InputProcess-Output model (see Casasola-Martinez and Cardone-Riportella; Gladstein, 1984; Stock, 2014). This dictates that a variety of inputs together influence intragroup processes, which in turn affect team outputs (Barrick, Bradley \& Colbert, 1998). A competing and commonly used alternative is the IMOI (Input-Mediator-Output-Input) model developed by Ilgen, Hollenbeck, Johnson, and Jundt (2005). The IMOI model is however not suitable to be used in the present study because of the insufficient number of primary studies available to establish a robust result in meta-analyses. On the contrary, 
van Knippenberg, Dreu and Homan (2004) developed the categorization-elaboration model (CEM) to address the issue of why diversity research has yielded inconsistent findings in teamwork. CEM proposes that team diversity is most likely to lead to elaboration of task-relevant information and perspectives when the team has strong communication and decision-making components. Thus, by combining both the IPO model and CEM, the present article undertakes a meta-analytical review of the role of communication (Process) in the relationship between team diversity (Input/Categorization) and team performance volatility (Output/Elaboration), to shed light on how they constitute the resilient organization.

The present article is thus focused at this team level of analysis, and makes several important contributions. First, from a theoretical perspective, it provides a conceptual clarification of communication based on two aspects: frequency and openness of communication. Second, to understand further the relationships among team diversity, communication and team performance, a systematic review of diversity attributes is proposed, drawing a clear distinction between cognitive abilities, social differences, and other dimensions of diversity (see Mannix \& Neale, 2005). Third, from an empirical point of view, the article analyzes separate effects of different types of diversity attributes - also distinguishing between social category differences and differences in knowledge skills and abilities - on communication, conceived in its features of both frequency and openness. Fourth, the role of these two different aspects of communication on team performance is tested; this concerns the triadic relationship of diversity, communication, and team performance, as derived from a significant volume of empirical research on the theme to create a more comprehensive picture of the IPO model of team diversity-communication-team performance. Thus, the perspective taken in this study is the workplace constitution of organizational resilience.

This article is protected by copyright. All rights reserved. 


\section{Organizational resilience at the workplace}

Organizational resilience at the workplace, or simply known as workplace resilience, has emerged from understanding the human resource management perspective of making the internal dynamics of an organization flexible, agile and dynamic, to improve the whole organization's prospects of survival amid hard external environmental conditions (see Lengwick-Hall et al, 2011). This places a reliance on the processes and policies in place that constitute the human resource (HR) management system. These dictate the working principles and behaviors that together form the organizational capacity for resilience. Lengwick-Hall et al (op cit: p. 249) outline the numerous components that relate to these, such as, teamwork, open communication, fitness/wellness, among others. Similarly, taking the components of robustness, agility and integrity, Bouaziz and Hachicha (2018) find that they have a positive relationship with various HRM practices, such as participation and staffing needs, which are all core elements of teamwork, suggesting the importance to focus on the micro-practices at the people level. Xiao and Cao (2017) go further in opening up the processes box (that lead to the recovery output) to argue specifically the different factors that relate to resilience between the organization, group/team and individual level. For the group/team level, psychological safety and accountability are the crucial elements, signaling the need to share knowledge and be cohesive (such as having good communication cultures).

Workplace resilience can be traced back to the treatment of human psychological capital (see Luthans, 2002; Luthans et al., 2015) as a valuable organizational competence, but it has been argued that there has been limited integration of different theoretical perspectives that link individual effort to team performance and organizational resilience (King et al., 2016). Seen as an incubation process for the practice of resilience (ibid), more research must focus on the psychological state of individuals to improve workplace resilience. In proposing four configurations comprised of reactive and proactive levels of preparation for the threat, against rigid and agile adaptations of the organization, as a twoby-two matrix, Burnard et al (2018) characterize the resilient-focused organization as being "flexible, 
prepared [and] able to learn" but "requires continued engagement with stakeholders and evolving processes" (p. 357). This seems to suggest the need of understand intergroup relations within the organization, particularly identifying which parts of the organization (and how they) are affected something termed 'the geography of strain' by Kahn et al (2018). They argue that different types of adversity affect different parts of the organization differently, so different groups, teams and functions within it are responsible for responding to the adversity in different ways, rather than a homogenous and holistic response from the organization. Despite identifying three possible states of organizational resilience as outcomes of how strain in the organization is managed, the one least vulnerable to crises is the outcome of strongly coordinated resources and synchronized efforts.

A significant body of research has emerged on how organizations should design and coordinate heterogeneous teams in order to gain such a competitive advantage (eg. Glassop, 2002) and team resilience (Meneghel, Martinez \& Salanova, 2016). It is also generally recognized that heterogeneous teams can promote innovation, creativity, and problem solving (eg. Perry-Smith \& Shalley, 2014; Somech \& Drach-Zahavy, 2013), which have also been applauded as key components of organizational resilience (Castellacci, 2015). However, sometimes they can also generate negative effects when the dissimilarities among team members trigger conflicts, divisions, and dissolution (Marin, Schilpzand, Kirkman, Ivanaj \& Ivanaj, 2013), or simply do not have any significant impact on performance (Homberg \& Bui, 2013). It would seem, a main challenge in teamwork practices is to communicate effectively, in order to coordinate and orchestrate the team members to accomplish organizational tasks successfully. So, to configure it additionally to establish greater resilience for the organization requires an established and prominent connection between that configuration and firm performance.

Nowhere more prominent than in the field of communications research has the role and importance of communication itself been researched extensively, not the least for their contribution to organizational resilience. While commenting on the specific use of information and communication technology (ICT) in the context of recovering from natural disaster (Hurricane Katrina), Chewning et al (2012) argue at the heart of effective teamwork is the ability to improve communication methods.

This article is protected by copyright. All rights reserved. 
The process of New Orleans' recovery relied heavily on improving open and more frequent communication and information flows that led to information sharing, connection and resource acquisition - all of which are also applicable to, and can assist, an organization in alternative recovery contexts.

Communication - both openly (with freedom) and frequently (number of times) - is at the heart of establishing social and formal coordination (Lai, Lam \& Lam, 2013) and assists sustainable business practices (Ortiz-de-Mandojana \& Bansal, 2016). It is therefore a pivotal process to analyze for the extensive comprehension of resilience (Sterbenz et al., 2010). However, some management scholars seem to have downplayed the direct role of communication in building resilience in organizations (eg. Fredrickson \& Losada, 2005; Leonardi, 2014; Cornelissen, Mantere \& Vaara, 2014). In a presidential address to the readership of the Journal of Communication, Buzzanell (2010) presented five different communicative processes for building resilience at the individual level during different life experiences, but which can apply in organizational settings if individuals are diverse, particularly in professional firms for which the demarcation between work and private life is blurred. Among others, she proposed the need to craft normalcy, affirm identity anchors and use communication networks. In so doing, resilience can be cultivated beyond the individual to firm level - ie. "across micro-meso-macro levels for a robust adaptive-transformative design and implementation" (Buzzanell, 2018, p. 16). Building on this viewpoint and suggesting that organizations are either anchored-resilient (firms with identity anchors that help them bounce back to ordinary daily life after adversity) or adaptive-resilient (firms that view disruptions as normal and ready to adapt in the face of adversity), Ishak and Williams (2018) argue that communication processes operate differently depending on these types, and they are difficult to be measured and quantified. For this reason, we examine directly the effect of communication on team performance measures, as integral components of organizational resilience.

This article is protected by copyright. All rights reserved. 


\section{Hypotheses Development: Organizational Resilience Framework}

\section{From Teamwork's Communication to Organizational Resilience}

Chewning et al's (2010) study is one of few studies that investigated organizational resilience in connection with (ICT) communication (see also Knittel and Stango, 2011). The extant literature therefore offered limited understanding of the role of communication in the creation of resilience at either team/workplace or organizational level. But armed with the knowledge that communication is somehow present in the relationship, the present study systematically unfolds the role of communication in the teamwork process for the context of team diversity and team performance.

Understanding of teamwork processes and their dimensionality is important for two main reasons. First, it is "informative about the processes underlying the influence of work group diversity (i.e. moderator effects observed may corroborate conclusions about the processes in operation)" (van Knippenberg \& Schippers, 2007, p. 519). Second, it can generate better suggestions for managers on ways to improve the functioning and effectiveness of teams in their organizations (Carmeli, Friedman, \& Tishler, 2013). These, in turn, establish a positive affectivity in team effectiveness and influence citizenship behavior in organizations, which respectively are found to improve resilience (Kaplan, Laport \& Waller, 2013; Lai, Lam \& Lam, 2013; Stephens, Heaphy, Carmeli, Spreitzer, \& Dutton, 2013). In this vein, several meta-analysis studies have been conducted recently to understand teamwork processes and their dimensionality (eg. Bell, Villado, Lukasik, Belau, \& Briggs, 2011; de Church \& Mesmer-Magnus, 2010a and 2010b; de Wit, Greer \& Jen, 2012; Homberg \& Bui, 2013; Hulsheger, Anderson, \& Salgado, 2009; Le Pine, Piccolo Jackson, Mathieu \& Saul, 2008; MesmerMagnus \& de Church, 2009; Schneid, Isidor, Li \& Kabst, 2015; Schneid, Isidor, Steinmetz \& Kabst, 2016).

Communication has long been considered a significant tool for teamwork functioning and coordination (Mintzberg, 1973) since it brings people together and encourages information exchange and knowledge-sharing through networking, documenting, and organizing (Cummings, 2004).

This article is protected by copyright. All rights reserved. 
Communication has the potential to enhance team performance by allowing the acquisition and exchange of salient knowledge among team members (Leonardi, 2014; Mesmer, Magnus \& de Church, 2009). More specifically, 'team communication' describes members' interactions directed toward task accomplishment, which in turn play a crucial role in the transformation of cognitive and emotional inputs into outcomes (Cornelissen, Mantere \& Vaara, 2014). The extant literature has identified an unresolved puzzle of controversial findings on the magnitude of the effects generated by the different types of team diversity on performance and the direction that teams take through different types of communication.

\section{Theoretical Approach to Team Diversity}

Team diversity refers to the distributional differences between team members on a common attribute (Harrison \& Klein, 2007). Despite the variety of literature dealing with the concept of diversity, most of the existing contributions classify individual differences under a specific two-fold approach. Scholars have considered the distinction between demographic and non-demographic attributes (Townsend \& Scott, 2001), that between readily detected/underlying and task-related/relationsoriented attributes (Milliken \& Martins, 1996), and that between surface-level categorization and deep-level categorization (Harrison, Price \& Bell, 1998).

Mannix and Neale (2005) propose a multi-category classification to extend the spectrum of the diversity construct. This categorization includes: (a) social-category differences (race, ethnicity, gender, age, religion, sexual orientation, and physical abilities); (b) differences in knowledge, skills, and abilities (education, functional knowledge, information or expertise, training, experience, and abilities); (c) differences in values or beliefs (cultural background and ideological beliefs); (d) personality differences (cognitive style, affective disposition, and motivational factors); (e) organizational or community-status differences (tenure or length of service and title); and (f) differences in social and network ties (work-related ties, friendship ties, community ties, and in-group memberships). Their classification is adopted in the present research as it enables distinction between 
the types of diversity and their attributes. It allows for a better assessment of the effects of different categories on the communication process and team performance. The focus is specifically on the first two categories: social-category differences (hereafter: SCs) and differences in knowledge, skills, and abilities (hereafter: KSAs). This is because these two categories are the most recurrent ones in the studies found for the present meta-analysis, and there were not enough empirical studies found that focused on the remaining three types of diversity. In accordance with the CEM and IPO model, the present research considers both KSA and SC attributes as the antecedents that either improve or hinder communication from transforming individual differences into performance outcomes.

\section{Communication and its Role as a Teamwork Process}

Communication is crucial in effective teamwork for numerous reasons. These are, first, because it is a pervasive process for the organizational structure that involves all the activities and all members of an organization (Chewning, Lai \& Doerfel, 2013). Second, communication helps to clarify how a team allocates and orchestrates its tasks interpersonally to accomplish them and perform effectively (Barrick et al., 2007). Third, communication is responsible for the acquisition of distinctive knowledge by team members and can contribute to team performance (Mesmer-Magnus \& de Church, 2009). Fourth and lastly, the extant literature has been inconsistent in defining the role of communication in teamwork, despite the former three reasons being consistent with Chewning et al in organizational resilience in natural disaster response. In defining communication, two major aspects of the communication construct have been examined in great depth: the frequency of communication and the openness of communication. Both these aspects are crucial for fast and effective communication (Katz, 1982). The former can be defined as the number of interactions occurring among and between team members in a certain context, while the latter refers to the degree of freedom in the communication between team members (Hinds \& Mortensen, 2005).

On the one hand, frequency of communication is generally considered a direct channel through which to achieve more efficient information- and knowledge-sharing processes. On the other 
hand, openness of communication might have an indirect impact on team performance, encouraging for instance, the depth of team information processing, the opportunity to share unique information, and the team's socio-emotional functioning (Mesmer-Magnus \& de Church, 2009). In the case of team conflict, spontaneous and open communication might mitigate the internal friction, allowing team members to share information, and thus promote a collaborative and trustful environment (Hinds \& Mortensen, 2005).

Frequency and openness of communication can affect team performance in different ways since they involve multiple interactions within the team and in relation to the outside environment. This distinction is necessary in discerning between internal and external communication, while the former refers to the patterns of interactions between team members (Pinto \& Pinto, 1990), and the latter concerns the interactions of team members outside the team (Keller, 2001). The rationale for this distinction lies in the potentially different processes and mechanisms of knowledge acquisition and sharing (Cohen \& Bailey, 1997).

\section{Team Diversity and Communication}

Different types of diversity might have different impacts on team functioning. In line with the social categorization perspective (Williams \& O'Reilly, 1998), team members distinguish between similar in-group members and dissimilar out-group members. This means, similarities in demographic attributes might favor the extent of the cooperation among individuals and can contribute to higher team efficiency (Earley \& Mosakowsky, 2000). This is complementary to the similarity/attraction perspective (Jehn, Northcraft \& Neale, 1999) that focuses on similarity as the main determinant of interpersonal attraction, arguing that people prefer to work with similar rather than dissimilar peers (van Knippenberg \& Schippers, 2007).

Conversely, under the cognitive diversity lens, task related attributes offer greater cognitive resources to the group and generate different impacts on team performance (DeChurch \& Mesmer- 
Magnus, 2010); this is because teams with less homogenous resources might gain more leverage from a differentiated pool of knowledge and opinions (Bell et al., 2011).

\section{Social Categorization Perspective}

The literature highlights that demographic diversity and fewer job-related characteristics, such as age, gender, and race, intensify intragroup conflict, reduce cohesion, and consequently complicate internal communications and coordination (eg. Bell et al, 2011). Bell et al (ibid) believe these diversity attributes are more likely to contribute to social categorization processes that create intra-group emotional conflicts and in-group-out-group distinctions. In line with social psychology research, an individual is likely to exclude other persons or socialize with them through judgement of observable characteristics such as age, gender and race (Fiske \& Neuberg, 1990). In this regard, Pelled, Eisenhardt and Xin (1999) argue that once individuals are divided into categories based on SCs, it is more difficult for them to become disassociated from those categories than it is for individuals who differ in terms of KSA attributes, such as educational or functional background. In this way, it is expected that communication problems might arise when team members fall within different SCs categories. However, from a dynamic perspective, the effect of demographic characteristics might change over time. Team members who are reluctant to cooperate with consolidated social categories can be more inclined to interact "if the salience of surface-level demographic characteristics dissipates over time" and "demographically dissimilar group members begin to re-categorize themselves as fellow in-group members" (Chatman \& Flynn, 2001, p. 957). Thus, intra-group conflicts and communication problems related to social category differences may be attenuated, without affecting the team performance. For the present research, based on the social categorization perspective, it is hypothesized that:

Hla. Team diversity measured with SC attributes will have a negative impact on openness of communication.

This article is protected by copyright. All rights reserved. 
$H 1 b$. Team diversity measured with SC attributes will have a negative impact on frequency of communication.

\section{Cognitive Diversity Perspective}

Although homogeneous team members generally display a stronger affinity with team performance than heterogeneous team members (Ibarra, 1992), the diversity of job-related attributes (e.g. educational and background) can also bring a wider range of competencies and different perspectives to the group (Gladstein, 1984; Pelled, 1996). Unfamiliar language among people with dissimilar experiences, backgrounds, beliefs, and values can, however, generate difficulties in communication and team integration (Wiersema \& Bantel, 1992), and even conflicts (Lovelace, Shapiro, \& Weingart, 2001). Bunderson and Sutcliffe (2002) ascertain that teams composed of narrow functional specialists, rather than generalists with a broad functional experience, may encounter cross-functional communication and coordination difficulties. In line with these arguments, Huang (2009) suggests that the different functional proveniences in a team might explain the reluctance to communicate openly, since team members with different demographic backgrounds might prefer to build a common environment with a shared professional identity.

Despite the likelihood that heterogeneity might generate misunderstanding, conflict, and poor cohesion, the need to share technical communication to achieve a task may be enough to overcome some problems and might even positively influence both the frequency and openness of communication as ascertained by several empirical analyses (eg. Campion, Papper \& Medsken, 1996; Cummings, 2004; Keller, 2001; Smith et al, 1994; Zenger \& Lawrence, 1989). Grounded on these arguments, the following hypotheses are proposed:

H2a. Team diversity measured with KSA attributes will have a positive impact on openness of communication.

This article is protected by copyright. All rights reserved. 
$H 2 b$. Team diversity measured with KSA attributes will have a positive impact on frequency of communication.

\section{Communication Effects on Team Performance}

The difference between frequency of communication and openness of communication are distinguished from one another in order to formulate hypotheses on the relationship between communication and performance.

\section{Frequency of Communication on Team Performance}

Frequency is often used to measure the richness of communication among team members, which in turn contributes to project success (Ebadi \& Utterback, 1984; Hinds \& Mortensen 2005). However, a different viewpoint suggests that excessive frequency of communication can generate disagreement or unproductive behaviors within teams, thus decreasing team performance. Kratzer (2001), for instance, finds that higher frequency of communication might in fact reduce the performance of innovation teams, while, conversely, low frequency of communication may signal effective internal functioning, with little need for information exchange and clarification. Patrashkova-Volzdoska et al. (2003) synthesize these positions by suggesting that a moderate level of frequency is more efficient than low or high communication frequencies and explain the relationship between frequency of communication and team performance as an inverted U-shape. The prevailing view of the extant literature regards frequency of communication as beneficial for team performance. In this regard, Ancona and Caldwell (1992a) highlight the importance of communications for performance and teamwork outcomes through a major sharing of information, cognitive resources, and cross-fertilization of ideas. In the same vein, Keller (2001) finds that external frequency of communication is positively related to technical quality and schedule performance. Broedbeck (2001) argues that high levels of 
communication increase project performance particularly in the latter stages of the project life-cycle and when standardization of methods and tools is low. More recently, Howell and Shea (2006) find that communication activities predict a higher level of team performance. Consistent with these views, the following hypothesis is generated:

H3: Frequency of communication has a positive relationship with team performance.

\section{Openness of Communication on Team Performance}

There seems to be agreement in the literature that openness of communication is related to work group effectiveness (eg. Campion, Medsker, \& Higgs, 1993). Gladstein (1984) states that open communication - in conjunction with supportiveness, active leadership, training, and experience in the organization - is related to the way group members view their own level of satisfaction and performance within a team. Therefore, performance relates to the goodness of the match between the communication patterns and the requirements of the group task (Nieva, Fleishman, \& Rieck, 1978). As argued by Lovelace et al. (2001), the communication atmosphere develops because of both team members' attitudes and behaviors: this means that team members who feel or express doubts about anything can influence the cooperativeness or contentiousness of the entire team. The communication behaviors exhibited by a team can further influence each member's freedom to express such concerns and doubts, and subsequently generate positive outcomes from their information sharing (Neale \& Bazerman, 1991). Lovelace et al. (2001) ascertain that expressing doubts can moderate the negative effect of task disagreement on a team's effectiveness, while Bunderson and Sutcliffe (2002) posit that open information-sharing is likely to smooth frictions and conflicts in heterogeneous teams, and consequently enhance team performance. Following these arguments, the following is hypothesized:

H4: High openness of communication has a positive impact on team performance.

This article is protected by copyright. All rights reserved. 


\section{The Triadic Relationship between Diversity, Communication, and Team Performance}

Previous meta-analyses concerning communication and team performance (Bell et al., 2011; de Church \& Mesmer-Magnus, 2010b; Homberg \& Bui, 2013; Lin et al, 2017; Mesmer-Magnus \& de Church, 2009; Webber \& Donahue, 2001) have focused principally on team diversity, team performance and team effectiveness; they have not examined how the process of communication mediates the effect of diversity categorization on team performance volatility. For example, most of these meta-analyses (eg. Homberg and Bui, 2013; Lin et al., 2017) investigated the relationship between team diversity and team performance (through a different team diversity categorization and different types of team performance). Webber and Donahue (2001), de Church and Mesmer-Magnus (2010b) and Bell et al. (2011) investigated in all types of team, while Homberg and Bui (2013) and Lin et al. (2017) focused on top management teams. Mesmer-Magnus and de Church (2009) examined the process of team information sharing on team performance. Thus, extant meta-analyses have not extensively investigated the CEM and IPO model of team diversity-communication-team performance. Therefore, to advance previous understanding in this area, the linearity of the relationship between team diversity, communication and performance volatility is investigated in the present study.

Social-category differences can often lead to social categorization-based processes (founded on intergroup bias and negative attitudes toward dissimilar team members), which in turn are responsible for negative performance consequences (van Knippenberg \& Schippers, 2007). Contrarily, difficulties in knowledge, skills and abilities represent the cognitive resource base for a group, which are associated with activities such as information- and perspective-sharing and feedback, feedback generation and knowledge integration; these activities collectively explain the positive outcomes of team performance (Bell et al.; 2011 and Homberg \& Bui, 2013; Joshi \& Roh, 2009). Based on these two categories of team diversity on team performance, it is argued that an increase in the openness of communication can strengthen the effects of KSAs on team performance, while reducing the negative effect of SCs. The role of frequency of communication in the relationship between team diversity and team performance works in a similar way. Therefore, it is proposed:

This article is protected by copyright. All rights reserved. 
H5a: Frequency and openness of communication increase team performance for heterogeneous teams that display KSAs.

$H 5 b$ : Frequency and openness of communication reduce the negative effect of SCs on team performance.

\section{Methods}

\section{Literature Search}

A conventional literature review of the current position of organizational resilience was first undertaken to justify the need to identify papers on those specific variables relating to communication, team performance and organizational resilience. Then, manual and computer-based searches were performed to identify specific studies in relation to those variables to enable the meta-analysis. For the general understanding, online databases, such as ABI/INFORM, EconLit, Psycinfo, PsycLit, Business Source Complete, Google Scholar, and SSRN were used, and second, the major rated journals including Academy of Management Journal, Administrative Science Quarterly, Group Dynamics, Group and Organization Management, Journal of Applied Psychology, Applied Psychology: An International Review, Journal of Management Studies, Journal of Management, Journal of Organizational Behavior, Journal of Product Innovation Management, Management Science, Organization Science, Personnel Psychology, and Small Group Research were used to find relevant empirical studies. The choice of those scholarly and high prestige journals was a safe selection “because not all of journals have the same currency' (Homberg and Bui, 2013, p. 460). The specific key terms used in the computer search were: team (or group) diversity, team heterogeneity, team demography, team composition, team communication, team processes, team performance, team effectiveness, frequency of communication, and organizational resilience. Additional to these specific terms was the term knowledge sharing, since the literature adopted it as measure of openness of communication. After reviewing the online sources and the references section of the articles selected, book chapters and literature reviews (Cohen \& Bailey, 1997; Guzzo \& Dickson, 1996; Mathieu et al.

This article is protected by copyright. All rights reserved. 
2008; Milliken \& Martins, 1996) were checked, and a cross-reference search (by reading author citations) was conducted to identify other studies that could be of use in the meta-analysis, which had not resulted from the computer-based approach. Only studies focusing on communication characteristics in relationship with either team diversity or team performance were considered for the meta-analysis. This means that studies that do not provide relevant quantitative information of the diversity-communication link or communication-team performance link were excluded. Studies that reported qualitative results were excluded from the meta-analysis, although they were scrutinized for understanding their contribution within the field of organizational resilience. Following these research steps, the final sample consisted of 35 relevant and eligible empirical studies with 174 correlations used for the meta-analysis. Each of the 35 studies included at least one measure of communication.

\section{Data Set and Level of Analysis}

Based on the empirical literature, team performance included the following indicators: team performance, supervisor ratings, innovativeness, productivity, team effectiveness and efficiency, productivity, budget performance, efficacy, goal achievement, project efficiency, and project performance. The level of analysis was the group/team. Studies that aggregated the collected data from the individual level to the team level were also included in the sample, since both team performance and communication often concern collective perceptions of individual members.

\section{Meta-analysis Procedure}

Meta-analysis is a quantitative technique that aims to reconcile conflicting empirical results, to provide a clear picture of the current state of knowledge on a specific topic (Stanley, 2001). Furthermore, as pointed out by Homberg and Bui (2012), meta-analysis attempts to identify and calculate the true underlying empirical effect of a certain treatment or relationship.

This article is protected by copyright. All rights reserved. 
For this study, the random-effects meta-analysis procedure of correlations corrected individually for artifacts, proposed by Hunter and Schmidt (2004), was employed. Following this procedure, the untransformed effect-size estimates, $r$, were used to calculate the weighted mean correlation. To calculate the standard deviation of the population correlation $(S D r)$, the variance of the sample correlations was corrected by sampling error and artifact corrections. Therefore, the estimate of population variance is the residual variance after sampling errors and other artifacts were subtracted out. Corrections for unreliability were made in the case of communication and diversity (except for objective measures), and corrections for performance were adopted only in the case of self-reported performance measures. To avoid autocorrelation, the effect sizes available for the same attributes in more than one period in each study was averaged out. Finally, the 95\%-confidence interval was calculated by using the corrected population correlation and the standard deviation of the corrected population correlation. Field (2005) points out that the confidence intervals with Hunter and Schmidt's method tend to be narrow, but they also tend to be more accurate than those from other conventional methods (eg. Hedges and Olkin, 1985).

The results are reported for three different relationships, consistent with the IPO framework: (a) the effect of team diversity on team performance; (b) the effect of team diversity attributes on openness and frequency of communication; and (c) the impact of openness and frequency of communication on team performance.

Finally, to test hypotheses H5a and H5b, the means of frequency and openness of communication were divided for the scale used to measure them. In this way, all these measures comparable with each other are made available. The means for the new measures were calculated for each type of communication. Further, this measure was split in two groups: low and high frequency and openness of communication. In particular, "low communication" was classified as studies that exhibit a value for the communication measures above the mean value, and "high communication" was considered as studies with a value for the communication measures below or equal to the mean value. 


\section{Treatment of Resilience}

The resilience dimension in our analysis was accounted for by considering the level of team performance in the presence of uncertainty. Such uncertainty or high-pressure environment was measured by looking at the volatility of team performance. Thus, we expect to observe an increase in the effect of each type of communication on team performance in the cases with high uncertainty compared to the cases with low uncertainty. We instead expect to observe a lower effect of team diversity on communication in the case of high uncertainty. From a methodological viewpoint, our sample was therefore based on the standard deviation of team performance. For comparison purposes, the standard deviation was divided for the range of the scale used to measure team performance. Studies for which the scale was not available was dropped. Subsequently, the average standard deviation of team performance for all the studies was calculated. Finally, the category 'high uncertainty' was classified as those studies that exhibit a modified standard deviation above the mean value, while 'low uncertainty' was considered as those studies that have a modified standard deviation below or equal to the mean value.

\section{Publication Bias}

The problem of publication bias was addressed consistently with recent meta-analyses in organization research (eg. Borenstein, 2005; Hombert and Bui, 2013; Kepes et al., 2012). As explained by Stanley (2008, p. 104):

"Publication bias, or the "file drawer problem," is the consequence of choosing research papers for the statistical significance of their findings. "Statistically significant" results are often treated more favorably by researchers, reviewers and/or editors; hence, larger, more significant effects are over-represented."

This article is protected by copyright. All rights reserved. 
Procedures described by Stanley (2005) and Doucouliagos (2005) were employed to examine publication bias and the presence of a true effect. We used both funnel plots and the funnel asymmetry test (Egger et al., 1997) to investigate publication bias and small study effects. A funnel plot is a graphical representation of effect size against some measure of precision (usually either the inverse of standard error or sample size). Our test used the Fisher $\mathrm{Z}$ transformation of the correlation coefficient corrected for the artifacts (Hedges and Olkin, 1985). We then used the standard error of $\mathrm{Z}$ transformation as a measure of precision. Sterne and Egger (2001) argue that the standard error is preferable to the sample size. If there is any publication bias, a funnel plot will be symmetrical in shape. We also employed Egger's test, which is a formal statistical test of symmetry in a funnel plot. The null hypothesis for Egger's test is that symmetry exists in a funnel plot, while the alternative suggests the presence of asymmetry.

A further bias that can arise from the use of more than one finding from the same study is known as the data-dependence issue. As a robustness check, the average of all estimates that originated from a single study was taken to ensure an acceptable level of independence among the studies.

\section{Moderation analysis}

For the moderating analysis, we separated internal communication from external communication.

The rationale for this distinction is because these two dimensions of communication can lead to potentially different processes and mechanisms of knowledge acquisition and sharing (Cohen \& Bailey, 1997). Since the function and consequences of team internal and team external communications are quite distinct, mixing these aspects could alter the real relationships. Furthermore, we considered team type as a moderator of the relationship between communication and performance. The reason is that project teams are usually linked with high uncertainty compared with 
the other types of team. Therefore, both frequency and openness of communication can be specifically beneficial for the achievement of goals by project team members.

\section{Results}

Table 1 reports the set of analyses that examined the relationship between SCs, KSAs and openness of communication (H1a, H2a) and between SCs, KSAs and frequency of communication (H1b, H2b).

Table 1 shows that team diversity exerts a positive effect on openness of communication with the corrected population correlation, $\rho$, equal to 0.129 . While the $95 \%$-CI includes zero, instead we find that the effect size is significant when we consider the $90 \%$-CI $(0.004,0.254)$.

H1a predicts a negative relationship between SCs and openness of communication. Contrary to our expectations, a positive and significant relationship between the two constructs ( $\rho=$ 0.131) is found. Thus, H1a is not supported. It is also noticed that the sampling error appears to cause the variance of observed correlations to differ slightly from the expected value. H1b predicts a negative relationship between social categories' differences and frequency of communication. The results do not support this hypothesis since no significant relationship between SCs and frequency of communication is found. The $95 \%-\mathrm{CI}$ is in fact broad and includes zero.

$\mathrm{H} 2 \mathrm{a}$ predicts a positive relationship between KSAs with openness of communication. Consistent with $\mathrm{H} 2 \mathrm{a}$, a positive and significant impact of KSAs on openness of communication is found $(\rho=0.150,95 \%-\mathrm{CI}=-0.159,0.430)$. However, such an effect is not significant. Therefore, H2a is not supported. Also, in the case of frequency of communication, KSA exhibits a positive, but insignificant significant, effect, and so H2b cannot be supported.

This article is protected by copyright. All rights reserved. 
As these hypotheses concern the relationship between KSA and openness and frequency of communication, the percentage of variance attributed to sampling error and artifact is less than $50 \%$. This suggests the presence of heterogeneity in the sample. This could also explain why no significant effect for KSA differences by applying the Hunter-Schmidt procedure was found. Part of the problem can also be due to there being studies that reported more than one effect. To overcome possible datadependence issues, the correlations for team diversity and frequency of communication per study were averaged (Average ES per Study). Despite this, the 95\%-CI still includes zero. The same procedure was applied in the case of the relationship between team diversity and openness of communication. The 95\%-CI then became narrower than before, thereby strengthening the positive sign of the result between team diversity and openness of communication, mainly driven by SCD differences. By focusing solely on internal communication as a main moderator we found confirmation for the main results discussed above.

Table 2 reports the findings for $\mathrm{H} 3$ and $\mathrm{H} 4$ which investigate the effect of frequency and openness of communication on performance.

$\mathrm{H} 3$ predicted that frequency of communication increases team performance. The results show that frequency of communication has a positive relationship with team performance, so that as the frequency of communication increases, team performance also increases. The corrected population $(\rho)$ is equal to 0.199 . The $95 \%$-CI includes zero, but it is also skewed towards a positive value. When we calculated the average of the effect sizes from the same study, $\rho$ is 0.171 with $95 \%-\mathrm{CI}: 0,0.342$. Based on these considerations, we find support for H3. However, the results also indicate the need to explore further possible moderators that can reduce the variability of the effect size across the studies. Focusing on the level of uncertainty of team performance, our results reveal a stronger and significant effect of frequency of communication on team performance for teams with higher uncertainty (High Uncertainty) with $\rho=0.226$. Furthermore, the $90 \%$-CI does not include zero $(\rho=0.226$, $90 \%$ - 
$\mathrm{CI}=0.024,0.429$ ). A similar result is found when we solely considered the correlations for Project Teams. For that analysis, the $95 \%-\mathrm{CI}$ is also very broad and includes zero.

$\mathrm{H} 4$ predicts that openness of communication would be positively related to team performance. The results strongly support this hypothesis $(\rho=0.348,95 \%-\mathrm{CI}=0.064,0.633)$. Focusing on the level of uncertainty of team performance, our results reveal a stronger and significant effect of openness of communication on team performance for teams with low uncertainty $(\rho=0.395)$ compared to high uncertainty $(\rho=0.289)$. Such a positive effect is even higher for project teams $(\rho=0.424)$. In this case, the sampling error appears to cause the variance of observed correlations to differ slightly from the expected value. Finally, the overall corrected population correlation appears to be strengthened when we average out the correlations from the same studies ( $\rho=0.375$ with a $95 \%$-CI $=0.074,0.675$ ).

Finally, Table 3 reports the results of the triadic relationship between H5a and H5b. H5a states that frequency and openness of communication increase team performance for heterogeneous teams that display KSAs; while H5b states that frequency and openness of communication reduce the negative effects of SCs on team performance.

KSAs are not significantly related to performance $(\rho=0.043,95 \% \mathrm{CI}=-0.288,0.375)$. All the specifications for KSA differences and team performance are not significant as the $95 \%-\mathrm{CI}$ is too broad and includes zero, 0.380). Thus, H5a is not supported.

The effect of SCs on team performance is based on 23 effect sizes and the corrected population, $\rho$, is equal to 0.043 . For the majority of the analyses conducted for SCs and team performance we find that the sampling error appears to cause the variance of observed correlations to differ slightly from the expected value.

Both level of frequency of communication and high openness of communication appear to intensify the negative relationship between SCs and team performance. Therefore H5b is supported, 
but, consistent with other meta-analyses (for example Bell et al., 2011), the effect size for SCs is very small and close to zero. This suggests the existence of contrasting results on this issue.

The presence of publication bias was then investigated for all the main analyses. There is evidence that, generally, studies that do not report statistical significance tend not to be published (e.g. Ioannidis 1998). For this scope, the Fisher-Z for the sample-weighted mean correlation corrected for the artifacts was used. In particular, Figure 2 shows the plot of std error (y-axis) versus the effect size (x-axis). This figure assesses the presence of small studies reporting bias/publication bias, and determines "whether the areas where studies exist are areas of statistical significance and whether the areas where studies are potentially missing correspond to areas of low statistical significance. If studies appear to be missing in areas of low statistical significance, then it is possible that the asymmetry is due to publication bias" (Palmer et al., 2008, p. 243).

As H1a concerns the relationship between SCD differences and team performance, the funnel plot looks symmetrical. In the case of KSA differences and team performance, it seems that there are studies with higher standard errors missing on the right-side of the funnel. The results could be driven by the effect of small studies on the left-side of the funnel. This seems to be confirmed by Egger's test for small-study effects that reports a significant p-value at $5 \%$.

Conversely, focusing on the relationship between team diversity and both frequency and openness of communication, we notice that, if the area where studies are perceived to be missing, these are areas of high statistical significance. In this case, the publication bias is a less likely cause of the funnel asymmetry. In the case of team diversity and frequency of communication, Egger's test for small-study effects reports a significant p-value at $10 \%$. However, after controlling for the datadependence issue, by averaging the correlations frequency of communication and team diversity, the small studies effect is no longer statistically significant.

In the case of openness of communication and team performance there are missing studies in the regions of both low and high levels of statistical significance. Therefore, publication bias does not seem to be the only cause of funnel asymmetry. It may be possible that studies have been suppressed 
because of a mechanism based on two-sided p-values (Palmer et al., 2008). In the case of frequency of communication, it seems that there could be some missing studies in the area of non-significance for studies with medium-level standard errors. Therefore, there could be a potential publication bias effect. Egger's test for small-study effects does not indicate the presence of small studies effect with a significant $\mathrm{p}$-value at $5 \%$.

\section{Discussion}

This present article has presented an examination of the variables that relate to the internal team level workings of resilience in organizations. While the logic for the relationships is the outcome of gaps identified in the resilience literature, the inability to support several hypotheses is however indicative of a novelty with which the extant literature (not all of which were specifically organizational resilience derived) has not engaged strongly enough with the idiosyncrasies of resilience. This is a crucial recognition and distinction in the consideration of organizational resilience per se as opposed to resilience in organizations, where the latter context is the present research's contribution.

In the specific case, for example, of H1a being a significant predictor, but being positive in how SC diversity impacts upon the openness of communication, suggests that resilience is not higher when organizations are more rigid in terms of their social categories, but that greater diversity creates a more open-minded culture that improves performance. This supports early organizational resilience research on team heterogeneity, which extends to the significance of internal communication. The relationship between team diversity and performance found in the present study is consistent with the results of other former meta-analyses. For example, Bell et al. (2011) and Horwitz and Horwitz (2007) find that SCs do not have any significant impact on team performance; Homberg and Bui (2013) also establish no clear link between team diversity and performance in TMTs. One possible 
explanation for these controversial findings is because the relationship between team diversity and team performance is not a dyadic connection, but instead encompasses multidimensional processes which mediate and affect this connection, further supporting the view that resilience in organizations requires flexibility than rigidity.

Some aspects of SCs and KSAs have been clarified in considering the relationship between diversity and communication. Specifically, members of a team who have different experiences are likely to share information and communicate more openly than otherwise, particularly when dealing with a task that requires interconnections with outside of the team. Under complex conditions, team members are persuaded to share their expertise to accomplish the task. This suggests that resilience is built on the ability to manage internal complexity. However, as there were only a few correlations available from the extant literature, the complexity of the task has not been examined; neither has it for openness of communication nor for frequency of communication to substantiate this claim.

In contrast to the social categorization perspective, the findings demonstrate that SCs do not generate conflicts and frictions within a team, but rather favor openness of communication, particularly in the case of age diversity and race/ethnicity diversity. There are four possible explanations for the positive effect of the observed relationship. First, demographic diversity is negatively related to team performance only in situations where a social categorization translates into an intergroup bias in perceptions, evaluations, and social interaction (van Knippenberg, de Dreu \& Homan, 2004). When this intergroup bias is present, the team members display some reluctance to engage in open communication with dissimilar individuals (van Knippenberg, 1999). Because it is not yet understood when intergroup bias can occur, our evidence enforces the need for further examination of intergroup bias in the relationship between team demographic diversity and team performance literatures. Moreover, it remains unclear if social categorization processes can also stimulate group information so that dissimilar members can benefit from their informational diversity (Phillips \& Loyd, 2005). Second, the negative effects associated with diversity of social categories can change over time because people become better acquainted with each member of the group they belong to and become more experienced in working with each other (Harrison et al, 2002). 
Unfortunately, the empirical studies utilized in the present research did not consistently take team tenure into consideration, and therefore was not reported as a moderating variable in our analysis. Third, another potential explanation for the contrasting findings for the effect of intra-group SCs can be traced back to the creation of a unified team culture that facilitates internal communication (Earley \& Mosakowski, 2000). A final possible explanation for the positive relationship between age and openness of communication is because generational experiences within a team can influence the work values (Smola \& Sutton, 2002), which is rare in the conventional organizational resilience literature. The co-existence of different generational experiences can favor a socially shared cognition which exists in team and task understanding (van Knippenberg \& Schippers, 2007), and it can lead to greater cooperation between team members, further strengthening the argument that managed flexibility is important for a resilient organization (Burnard et al,, 2018). The results reveal that an increase in openness of communication can enhance team performance particularly for teams of small-medium size operating in manufacturing industries (consistent with Ingram and Glod, 2018). Frequency of communication has a positive but different impact on team performance depending on the team size. As expected, the interactions among team members (Keyton \& Beck, 2008) and the involvement of all the individuals (Smith et al., 1994) can be slightly more complicated in large teams, which is when resilience in organizations is more difficult to trace (following the 'geography of strain' argument on the imperative of intergroup relations of Kahn et al., 2018). Moreover, the frequency of communication has a positive but insignificant impact on team performance for the case of small-size teams, whereas it improves the effectiveness of the outcome only in the case of medium-size teams. Consequently, heterogeneous teams with cognitive differences that are likely to communicate more frequently in small teams do not however increase the overall team efficiency. These findings are consistent with the above as diversity and openness are attributable to flexibility vis-à-vis rigidity, which the present research is tending to signify in support of resilience.

This article is protected by copyright. All rights reserved. 


\section{Conclusion}

This article has presented an adaptive model, and tested it using meta-analysis, of the components that are important for a resilient organization. While only half of the proposed hypotheses were supported by the results, there is still a strong message to tell. SC diversity has a positive impact on the openness of communication (contrary to that hypothesized), which in turn leads to a higher performance output; this might be because the organization is more flexible in its approach, be more able to absorb any contingencies associated with crises and 'bounce back', hence making the organization more resilient.

The other hypotheses for which support was not found can also be attributed to the inherent limitations of meta-analysis research, from which the present study is also not exempted. These include our inability to find sufficient correlations in the extant literature to establish statistical significance to substantiate claims, and not all studies report all error coefficients to build a full appreciation of our hypothesized understandings. While the key contribution of the present research is to augment and offer a detailed examination of key components that constitute resilience in organizations (such as drawing literature on SC and KSA diversity, and communication), these publications had not necessarily discussed core issues of organizational resilience in their original research purposes; this might have affected the results, and accounted for why only half our hypotheses were supported.

Aside from the theoretical contributions, this study offers three key recommendations for practitioners who attempt to enhance organizational resilience through effective team composition. First, practitioners in organizations staffing team members with diverse cognitive abilities (such as experiences or education) should install a shared language and system of communication to overcome problems of misunderstanding caused by different professional expertise. Second, practitioners should also consider if increasing the frequency of communication for team members who have different cognitive abilities favors the accomplishment of the task. The number/frequency of 
interactions might depend on communicative problems rather than on task interdependence. Third, to increase the cooperation within a team, practitioners can employ individuals with different generational experience which in turn favors a socially shared cognition for the benefit of better task understanding. Future research may benefit from testing the credibility of these claims, either through meta-analysis or standalone research. For now, it is hoped these practical suggestions throw some light on the team operating dynamics of resilience in organizations, which this paper has presented from an applied psychology perspective, through a meta-analytical international review of extant literature.

\section{REFERENCES ${ }^{1}$}

Allen, T. J. 1971. Communication networks in R\&D laboratories. R\&D Management, 1: 14-21.

Allen, T. J. 1977. Managing the Flow of Technology: Technology Transfer and the Dissemination of Technological Information within the $R \& D$ Organization. Cambridge, MA: MIT Press.

*Ancona, D. G. \& Caldwell, D. F. 1992a. Demography and design: Predictors of new product team performance. Organization Science, 33: 321-341.

*Ancona, D. G. \& Caldwell, D. F. 1992b. Bridging the boundary: External activity and performance in organizational teams. Administrative Science Quarterly, 374: 634-665.

Annarelli, A. \& Nonino, F. 2016. Strategic and operational management of organizational resilience: current state of research and future directions, Omega, 62, 1-18.

${ }^{1}$ References marked with an asterisk (*) indicate studies included in the meta-analyses.

This article is protected by copyright. All rights reserved. 
Barasa, E., Mbau, R. \& Gilson, L. 2018. What is resilience and how can it be nurtured? A systematic review of empirical literature on organizational resilience, International Journal of Health Policy and Management, 7(6), 491-503.

*Barrick, M. R., Bradley, B. H. \& Colbert, A. E. 2007. The moderating role of top management team interdependence: Implications for real teams and working groups. Academy of Management Journal, 503: 544-557.

*Barrick, M. R., Stewart, G. L., Neubert, M. J. \& Mount, M. K. 1998. Relating member ability and personality to work-team processes and team effectiveness. Journal of Applied Psychology, 83: 377-391.

Bell, S.T, Villado, A.J, Lukasik, M.A., Belau, L., \& Briggs, A.L. 2011. Getting specific about demographic diversity variable and team performance relationships: A meta-analysis. Journal of Management, 373: 709-743.

Borenstein, M., Rothsetin, H \& Sutton, A. 2005. Publication bias in meta-analysis: Prevention, assessment and adjustments. Hoboken, NJ: Wiley.

Bouaziz, F. \& Hachicha, Z.S. 2018. Strategic human resource management practices and organizational resilience, Journal of Management Development, 37(7), 537-551.

*Brodbeck, F. C. 2001. Communication and performance in software development projects. European Journal of Work and Organizational Psychology, 10(1): 73-94.

*Bunderson, J.S., Sutcliffes, K.M. 2002. Comparing alternative conceptualizations of functional diversity in management teams: Process and performance effects. Academy of Management Journal, 455: 875-893.

Burnard, K., Bhamra, R. \& Tsinopoulos, C. 2018. Building organizational resilience: four configurations, IEEE Transactions on Engineering Management, 65(3), 351-362.

Buzzanell, P.M. 2010. Resilience: talking, resisting, and imagining new normalcies into being, Journal of Communication, 60, 1-14.

Buzzanell, P.M. 2018. Organizing resilience as adaptive-transformative tensions, Journal of Applied Communication Research, 46(1), 14-18.

*Campion M. A., Medsker G. J. \& Higgs A. C. 1993. Relations between work group characteristics and effectiveness: Implications for designing effective work groups. Personnel Psychology, 46: $82-50$

*Campion M. A., Papper E. M. \& Medsker G. J. 1996. Relation between work team characteristics and effectiveness: a replication and extension. Personnel Psychology, 49: 429-452.

Carmeli, A., Friedman, Y. and Tishler, A., 2013. Cultivating a resilient top management team: The importance of relational connections and strategic decision comprehensiveness. Safety Science, 51(1), pp.148-159.

Carmeli, A. \& Markman, G.D., 2011. Capture, governance, and resilience: strategy implications from the history of Rome. Strategic Management Journal, 32(3), pp.322-341.

This article is protected by copyright. All rights reserved. 
Casasola-Martinez M. J. \& Cardone-Riportella, C. 2009. Too Important to Fail: Do Banking Relationships Improve Spanish SMEs Credit Conditions? Universia Business Review, 12-29.

Castellacci, F. 2015, Institutional voids or organizational resilience? Business groups, innovation, and market development in Latin America, World Development, 70, 43-58.

*Chatman, J.A., Flynn, F.J. 2001. The influence of demographic heterogeneity on the emergence and consequences of cooperative norms in work teams. Academy of Management Journal, 445: 956974.

Chewning, L. V., Lai, C-H. \& Doerfel, M. L. 2013. Organizational resilience and using information and communication technologies to rebuild communication structures. Management Communication Quarterly, 27(2),

Cohen, S. G \& Bailey, D. E. 1997. What makes teams work: Group effectiveness research from the shop floor to the executive suite. Journal of Management, 233: 239-290.

Combs, J., Liu, Y., Hall, A., \& Ketchen, D. 2006. How much do high-performance work practices matter? A meta-analysis of their effects on organizational performance. Personnel Psychology. 59: $501-528$.

Cornelissen, J. P., Mantere, S. \& Vaara, E. 2014. The contraction of meaning: The combined effect of communication, emotions, and materiality on sensemaking in the Stockwell shooting. Journal of Management Studies, 51(5), 699-736.

Coutu, D.L. 2002. How resilience works, Harvard Business Review, 80(5), 46-56.

Cox, T. H. \& Blake, S. 1991. Managing cultural diversity: Implications for organizational competitiveness, Academy of Management Executive, 5: 45-56.

*Cummings, J.N. 2004. Work groups, structural diversity, and knowledge sharing in a global organization. Management Science, 503: 352-364.

Datta, D. K., Guthrie, J. P., \& Wright, P. M. 2005. Human resource management and labor productivity: Does industry matter? Academy of Management Journal. 48: 135-145.

de Church, L. A. \& Mesmer-Magnus, J. R. 2010a. Measuring shared team mental model: A metaanalysis. Group Dynamics: Theory, Research, and Practice 14 (1): 1-14.

de Church, L. A., \& Mesmer-Magnus, J. R. 2010b. The cognitive underpinning of effective teamwork: A meta-analysis. Journal of Applied Psychology 95 (1):32-53.

de Wit, F. R. C., Greer, L. L., \& Jehn, K. A. 2012. The paradox of intragroup conflict: A metaanalysis. Journal of Applied Psychology 97 (2): 360-90.

Dimas, I.D., Rebelo, T., Lourenco, P.R. \& Pereira Pessoa, C.I. 2018. Bouncing back from setbacks: on the mediating role of team resilience in the relationship between transformational leadership and team effectiveness, The Journal of Psychology, 152(6), 358-372.

*Earley, P. C. \& Mosakowski, E. 2000. Creating hybrid team cultures: an empirical test of transnational team functioning. Academy of Management Journal, 431: 26-49.

This article is protected by copyright. All rights reserved. 
*Ebadi, Y. M. \& Utterback, J. M., 1984. The effects of communication on technological innovation. Management Science, 30(5): 572-585.

Egger, M., Smith, G. D., Scheider, M., \& Minder, C. 1997. Bias in meta-analysis detected by a simple, graphical test. British Medical Journal, 316, 629-634.

Fleming, R.S. 2012. Ensuring organizational resilience in times of crisis, The Journal of Global Business Issues, 6(1), 31-34.

Field, A. P. 2005. Is the meta-analysis of correlation coefficients accurate when population correlations vary? Psychological Methods, 10, $444-467$.

Fiske, S. T. \& Neuberg, S. L. 1990. A continuum of impression formation, from category-based to individuating processes: Influences of information and motivation on attention and interpretation. Advances in Experimental Social Psychology, 23:1-74.

Fredrickson \& Losada, 2005. Positive affect and the complex dynamics of human flourishing. American Psychologist, 60(7), 678-686.

*Gajendran, R. S. \& Joshi, A. 2012. Innovation in Globally Distributed Teams: The Role of LMX, Communication Frequency, and Member Influence on Team Decisions. Journal of Applied Psychology, 97(6): 1252-1261.

Gebert, D., Boerner, S. \& Kearney, E. 2006. Cross-functionality and innovation in new product development teams: A dilemmatic structure and its consequences for the management of diversity. European Journal of Work and Organizational Psychology, 15(4): 431- 458

Gladstein, D. L. 1984. Groups in context: A model of task group effectiveness. Administrative Science Quarterly, 29: 499-517.

Gladstein, D. L., \& Reilly, N. P. (1985). Group decision making under threat: The tycoon game. Management Journal, 28, 613-627.

Glassop, L. I. 2002. The organizational benefits of teams. Human Relations, 552: 225-249.

*Glick, W. H., Miller, C. \& Huber, G. P. 1993. The impact of upper-echelon diversity on organizational performance. In G. P. Huber and W. H. Glick (Eds.), Organizational Change and Redesign: 176-214. New York: Oxford University Press.

Gucciardi, D.F., Crane, M., Ntoumanis, N., Parker, S.K., Thogersen-Ntoumani, C., Ducker, K.J., Peeling, P., Chapman, M.T., Quested, E. \& Temby, P. 2018. The emergence of team resilience: a multilevel conceptual model of facilitating factors, Journal of Occupational and Organizational Psychology, 91, 729-768.

Gunasekaran, A., Rai, B.K. \& Griffin, M. 2011. Resilience and competitiveness of small and medium size enterprises: an empirical research, International Journal of Production Research, 79(18), 5489-5509.

Guzzo R. A. \& Dickson M.W. 1996. Teams in organizations: Recent research on performance and effectiveness. Annual Review of Psychology, 47: 307-338.

This article is protected by copyright. All rights reserved. 
Hambrick, D. C., Cho, T. S. \& Chen, M., 1996. The influence of top management team heterogeneity on firms' competitive moves. Administrative Science Quarterly, 41: 659-684.

Harrison, D. A. \& Klein K. J. 2007. What's the difference? Diversity constructs as separation, variety, or disparity in organizations. The Academy of Management Review, 32: 1199-1228.

Harrison, D. A., Price, K. H. \& Bell, M. P. 1998. Beyond relational demography: Time and the effects of surface- and deep-level diversity on work group cohesion. Academy of Management Journal, 41: 96-107.

Harrison, D. A., Price, K. H., Gavin, J. H. \& Florey, A. T. 2002. Time, teams, and task performance: Changing effects of surface and deep-level diversity on group functioning. Academy of Management Journal, 45: 1029-1045.

Hedges, L. V, \& Olkin I. 1985. Statistical Methods for Meta-analysis. Orlando: Academic Press.

*Hinds, P. \& Mortensen, M. 2005. Understanding conflict in geographically distributed teams: The moderating effects of shared identity, shared context, and spontaneous communication. Organization Science, 163: 290-307

*Hoegl, M. \& Gemuenden, H. G. 2001. Teamwork quality and the success of innovative projects: A theoretical concept and empirical evidence. Organization Science, 124: 435-449.

Holling, C.S. 1973. Resilience and stability of ecological systems, Annual Review of Ecology and Systematics, 1-23.

Homberg, F. \& Bui, H. T. M. 2013. Top management team diversity: A systematic review. Group and Organization Management 38 (4): 455-79.

Horwitz, S. K. \& Horwitz, I. B. 2007. The effects of team diversity on team outcomes: A metaanalytic review of team demography. Journal of Management, 33: 987-1015.

*Howell, J. M. \& Shea C. M. 2006. Effects of champion behavior, team potency, and external communication activities on predicting team performance. Group and Organization Management, 312: $180-211$.

*Huang, C. C. 2009. Knowledge sharing and group cohesiveness on performance: An empirical study of technology R\&D teams in Taiwan. Technovation, 29: 786-797

Hulsheger, U. R., Anderson, N., and Salgado, J. F. 2009. Team-level predictors of innovation at work: A comprehensive meta-analysis spanning three decades of research. Journal of Applied Psychology 94 (5): 1128-1145.

Hunter, J. E. \& Schmidt F.L. 2004. Methods of Meta-analysis: Correcting Error and Bias in Research Findings, $2^{\text {nd }}$ edition. Thousand Oak, California: Sage Fabrication Ink.

*Hyatt, D. E. \& Ruddy, T. M. 1997. An examination of the relationship between work group characteristics and performance: One more into the breech. Personnel Psychology, 50(3): 553-585.

Ibarra, H. 1992. Homophily and differential returns: Sex differences in network structure and access in an advertising firm. Administrative Science Quarterly, 37: 422-447.

This article is protected by copyright. All rights reserved. 
Ilgen, D. R., Hollenbeck, J. R., Johnson, M. , \& Jundt, D. 2005. Team in organizations: From inputprocess-output models to IMOI models. Annual Review of Psychology, 56: 517-543.

Ingram, T. \& Glod, G. 2018. Organizational resilience of family business: case study. Economics and Law, 17(1), 57-69.

Ioannidis, J. P. 1998. Effect of the statistical significance of results on the time to completion and publication of randomized efficacy trials. Journal of the American Medical Association, 279: 281286.

Ishak, A.W. \& Williams, E.A. 2018, A dynamic model of organizational resilience: adaptive and anchored approaches, Corporate Communications: An International Journal, 23(2), 180-196.

Jehn, K. A., Northcraft, G. B. \& Neale, M. A. 1999. Why differences make a difference: A field study of diversity, conflict, and performance in workgroups. Administrative Science Quarterly, 44: 741763.

Joshi, A. \& Jackson, S. E. 2003. Managing workforce diversity to enhance cooperation in organizations. In M. A. West, D. Tjosvold, and K. Smith (Eds.), International Handbook of Organizational Teamwork and Cooperative Working: 277-296. New York: Wiley.

Joshi, A., \& Roh, H. 2009. The role of context in work team diversity research: A meta-analytic review. Academy of Management Journal 52 (3): 599-627.

Kahn,, W.A., Barton, M.A., Fisher, C.M., Heaphy, E.D., Reid, E.M. \& Rouse, E.D. 2018. The geography of strain: organizational resilience as a function of intergroup relations, Academy of Management Review, 43(3), 509-529.

Kaplan, S., Laport, K. \& Waller, M.J. 2013, The role of positive affectivity in team effectiveness during crises, Journal of Organizational Behavior, 34, 473-491.

*Katz, R. 1982. The effects of group longevity on project communication and performance. Administrative Science Quarterly, 271: 81-104.

*Keller, R. T. 2001. Cross-functional project groups in research and new product development: Diversity, communications, job stress, and outcomes. Academy of Management Journal, 44(3): 547-555.

Keyton, J. 2006. Communicating in Groups: Building Relationships for Group Effectiveness, $3^{\text {rd }}$ Edition. New York: Oxford University Press.

Keyton, J. \& Beck, S. J. 2008. Team attributes, processes and values: A pedagogical framework. Business Communication Quarterly, 71(4): 488-504.

Kepes, S., Banks, G.C., McDaniel, M., \& Whetzel, D.L. 2012. Publication bias in the organizational sciences. Organizational Research Methods, 15, 624-662

King, D. D., Newman, A. \& Luthans, F. (2016). Not if, but when we need resilience in the workplace. Journal of Organizational Behavior, 37(5), 782-786.

This article is protected by copyright. All rights reserved. 
*Kirkman, B. L., Benson, R., Tesluk, P.E. \& Gibson C. B. 2004. The Impact of Team Empowerment on Virtual Team Performance: The Moderating Role of Face-to-Face Interaction. The Academy of Management Journal, 47(2): 175-192.

Knittel, C. R. \& Stango, V. 2011. Strategic incompatibility in ATM markets. Journal of Banking \& Finance, 35, 2627-2636.

Kratzer, J. 2001. Communication and Performance: An Empirical Study in Innovation Teams. Amsterdam: Thesis Publishers.

*Kratzer, J., Leenders R. T. H. J. \& van Engelen J. M. L. 2004. Stimulating the potential: Creative performance and communication in innovation teams. Creativity and Innovation Management, 131: 63-71.

Lai, J. Y. M., Lam, L. W. \& Lam, S. S. K., 2013, Organizational citizenship behavior in work groups: a team culture perspective, Journal of Organizational Behavior, 34, 1039-1056.

* Lee, P., Gillespie, N., Mann, L. \& Wearing, A. 2010. Leadership and trust: Their effect on knowledge sharing and team performance. Management Learning, 41(4): 473-491.

Lengnick-Hall, C.A. \& Beck, T.E. 2005. Adaptive fit versus robust transformation: how organizations respond to environmental change, Journal of Management, 31(5), 738-757.

Lengnick-Hall, C.A., Beck, T.E. \& Lengnick-Hall, M.L. 2011. Developing a capacity for organizational resilience through strategic human resource management, Human Resource Management Review, 21, 243-255.

LePine, J. A., Piccolo, R. F., Jackson, C. L., Mathieu, J. E. \& Saul, J. R. 2008. A meta-analysis of teamwork processes: Tests of a multidimensional model and relationships with team effectiveness criteria. Personnel Psychology, 61: 273-307.

Leonardi, P. M. 2014. Social media, knowledge sharing, and innovation: Toward a theory of communication visibility. Information Systems Research, 25(4), 796-816.

*Lievens, A. \& Moenaert, R.K. 2000. Project team communication in financial service innovation. Journal of Management Studies, 37(5): 733-766.

Lin, L., Madison, K., Kraiczy, N. D., Kellermanns, F. W., Crook, T. R. \& Xi, J. 2017. Entrepreneurial team composition characteristics and new venture performance: A meta-analysis. Entrepreneurship Theory and Practice, 41(5), 743-771.

*Ling, Y. \& Kellermanns, F.W. 2010. The Effects of Family Firm Specific Sources of TMT Diversity: The Moderating Role of Information Exchange Frequency. Journal of Management Studies, 47(2), 322-344.

*Lovelace, K., Shapiro, D. L. \& Weingart, L. R. 2001. Maximizing cross-functional new product team's innovativeness and constraint adherence: A conflict communications perspective. Academy of Management Journal, 44(4): 779-793.

Luthans, F. 2002. The need for and meaning of positive organizational behavior, Journal of Organizational Behavior, 23, 695-706.

This article is protected by copyright. All rights reserved. 
Luthans, F., Avey, J.B., Avolio. B.J. \& Paterson, S. 2010, The development and resulting performance impact of positive psychological capital, Human Resource Development Quarterly, 21, 41-66.

Manfield, R.C. \& Newey, L.R. 2018. Resilience as an entrepreneurial capability: integrating insights from a cross-disciplinary comparison, International Journal of Entrepreneurial Behavior and Research, 24(7), 1155-1180.

Mannix, E. \& Neale, M.A. 2005. What differences make a difference? The promise and reality of diverse teams in organizations. Psychological Science in the Public Interest, 6: 31-55.

Marin, L. L., Schilpzand, M. C., Kirkman, B. L., Ivanaj, S., \& Ivanaj, V. 2013. A contingency view of the effects of cognitive diversity on tam performance: The moderating roles of team psychological safety and relationship conflict. Small Group Research 44(2):96-126.

Mathieu , J., Maynard, M. T. \& Gilson, L. 2008. Team effectiveness 1997-2007: A review of recent advancements and a glimpse into the future. Journal of Management, 34(3): 410-476.

Meneghel, Martinez \& Salanova, 2016. Job-related antecedents of team resilience and improved team performance. Personnel Review, 45(3), 505-522.

Mesmer-Magnus, J. R. \& deChurch, L. A. 2009. Information sharing and team performance: A metaanalysis. Journal of Applied Psychology, 94(2): 535-546.

Milliken, F. \& Martins, L. 1996. Searching for common threads: Understanding the multiple effects of diversity in organizational settings. Academy of Management Review, 21: 402-433.

Mintzberg, H. 1973. The nature of managerial work. New York: John Wiley.

Neale, M. A. \& Bazerman, M. H. 1991. Cognition and rationality in negotiation. New York: The Free Press.

Nieva, V. F., Fleishman, E. A., \& Rieck, A. 1978. Team Dimensions: Their Identity, Their Measurement and Their Relationships. Washington, DC: Response Analysis Corporation, Advanced Research Resources Organization.

*Patrashkova-Volzdoska, R. R., McComb, S.A. Green, S.G. \& Compton, W.D. 2003. Examining a curvilinear relationship between communication frequency and team performance in crossfunctional project teams. IEEE Transactions on Engineering Management, 503: 262-269.

Ortiz-De-Mandojana, N. \& Bansal, P. 2016, The long-term benefits of organizational resilience through sustainable business practices, Strategic Management Journal, 37(8), 1615-1631.

Pelled, L. H., Eisenhardt, K. M. \& Xin, K. R. 1999. Exploring the black box: An analysis of work group diversity, conflict, and performance. Administrative Science Quarterly, 44: 1-28.

Perry-Smith \& Shalley, 2014. A social composition view of team creativity: The role of member nationality-heterogeneous ties outside of the team. Organization Science, 25(5), 1434-1452.

Pfeffer, J. \& O'Reilly, C. 1987. Hospital demography and turnover among nurses. Industrial Relations. 36: 158-173.

This article is protected by copyright. All rights reserved. 
Phillips, K. W. \& Loyd, D. L. 2006. When surface and deep-level diversity collide: The effects on dissenting group members. Organizational Behavior and Human Decision Processes. 99(2): 143160

Pinto, M. B. \& Pinto, J. K. 1990. Project team communication and cross functional cooperation in new program development. Journal of Product Innovation Management, 7: 200-212.

*Puck, J., Rygl, D. \& Kittler, M. 2006. Cultural antecedents and performance consequences of open communication and knowledge transfer in multicultural process-innovation teams. Journal of Organizational Transformation and Social Change, 3(2): 223-241.

*Polzer, J. T., Crisp, C. B., Jarvenpaa, S. L., \& Kim, J. W. 2006. Extending the faultline model to geographically dispersed teams: how collocated subgroups can impair group functioning. Academy of Management Journal, 49 (4): 679-692.

Ruiz-Martin, C., Lopez-Paredes, A. and Wainer, G. 2018. What we know and do not know about organizational resilience, International Journal of Production Management and Engineering, 6(1), $11-28$.

Schneid, M., Isidor, R., Steinmetz, H., \& Kabst, R. 2016. Age diversity and team outcomes: A quantitative review. Journal of Managerial Psychology, 31(1), 2-17.

Schneid, M., Isidor, R., Li, C., \& Kabst, R. (2015). The influence of cultural context on the relationship between gender diversity and team performance: A meta-analysis. International Journal of Human Resource Management, 26(6), 733-756.

*Smith, K. G., Smith, K. A., Olian J. D., O’Bannon D. P. \& Scully, J. A. 1994. Top management team demography and process: The role of social integration and communication. Administrative Science Quarterly, 39: 412-438.

Smola, K. W. \& Sutton, C.D. 2002. Generational differences: revisiting generational work values for the new millennium. Journal of Organizational Behavior, 234: 363-382.

Somech \& Drach-Zahavy, 2013. Translating team creativity to innovation implementation: The role of team composition and climate for innovation. Journal of Management, 39(3),

*Srivastava, A., Bartol, K.M., Edwin, K., \& Locke, E.A. 2006. Empowering leadership in management teams: effects on knowledge sharing, efficacy, and performance. Academy of Management Journal, 49(6): 1239-1251.

Stephens, J.P., Heaphy, E.D., Carmeli, A., Spreitzer, G.M. and Dutton, J.E., 2013. Relationship quality and virtuousness: Emotional carrying capacity as a source of individual and team resilience. Journal of Applied Behavioral Science, 49 (1), 13-41.

Sterbenz, J. P. G., Hutchison, D., Cetinkaya, E. K., Jabbar, A., Rohrer, J. P. Scholler, M. \& Smith, P. 2010. Resilience and survivability in communication networks: Strategies, principles, and survey of disciplines. Computer Networks, 54, 1245-1265.

*Stewart, G. L. \& Barrick M. R. 2000. Team structure and performance: Assessing the mediating role of intrateam process and the moderating role of task type. Academy of Management Journal, 43(2): $135-148$

This article is protected by copyright. All rights reserved. 
Stewart G. L. 2006. A meta-analytic review of relationships between team design features and team performance. Journal of Management, 32: 29-54.

Stock, R. M. 2014. How should customers be integrated for effective interorganizational NPD teams? An Input-Process-Output perspective. Journal of Product Innovation Management, 31(3), 535551.

Sundstrom, E., deMeuse, K. P. \& Futrell, D. 1990. Work teams: Applications and effectiveness, American Psychologist, 45: 120-133.

Stanley, T. D. 2005. Beyond publication bias. Journal of Economic Surveys, 19, 309-345.

Sterne, J. A. C. \& Egger, M. 2001. Funnel plots for detecting bias in meta- analysis: guidelines on choice of axis. Journal of Clinical Epidemiology 54(10): 1046-1055.

Townsend, A. \& Scott, K. 2001. Team racial composition, member attitudes, and performance: A field study. Industrial Relations, 40: 317-337.

Tushman, M. L. 1979. Impacts of perceived environmental variability on patterns of work related communication. Academy of Management Journal, 22(3): 482-500.

Tukamuhabwa, B.R., Stevenson, M., Busby, J. \& Zorzini, M. 2015. Supply chain resilience: definition, review and theoretical foundations for further study, International Journal of Production Research, 53(18), 5592-5623.

*Van Der Vegt, G., S. \& Bunderson, J. S. 2005. Learning and performance in multidisciplinary teams: The importance of collective team identification. Academy of Management Journal, 48(3): 532547.

van Knippenberg, D., Dd Dreu, C., \& Homan, A. 2004. Work group diversity and group performance: An integrative model and research agenda. Journal of Applied Psychology, 89: 1008-1022.

van Knippenberg D., Schippers M. C. 2007. Work group diversity. Annual Reviews, 58: 515-541.

Webber S. S. \& Donahue L. M. 2001. Impact of highly and less job-related diversity on work group cohesion and performance: A meta-analysis, Journal of Management, 27: 141-162.

Verreynne, M-L., Ho, M. \& Linnenluecke, M. 2018. Editorial for the special issue on: organizational resilence and the entrepreneurial firm, International Journal of Entrepreneurial Behavior and Research, 24(7), 1122-1128.

West, B.J., Patera, J. M., \& Carsten, M. K. 2009. Team level positivity: investigating positive psychological capacities and team level outcomes, Journal of Organizational, 30(2): 249-267.

Wiersema, M. F. \& Bantel, K.A. 1992. Top management team demography and corporate strategic change. Academy of Management Journal, 35(1): 91-121.

William, K. Y., \& O'Reilly, C. A. 1998. Demography and diversity in organizations: A review of 40 years of research. In L. L. Cummings, \& B. M. Staw (Eds.), Research in Organizational Behavior, Vol. 20: 77-140. Greenwich, CT: JAI Press.

Xiao, L. \& Cao, H. 2017. Organizational resilience: the theoretical model and research implication, ITM Web of Conferences, 12, 1-4.

This article is protected by copyright. All rights reserved. 
*Zenger, T. R. \& Lawrence, B. S. 1989. Organizational demography: The differential effects of age and tenure distributions on technical communication. Academy of Management Journal, 32(2): 353-37.

Figure 1: Theoretical Framework of Communication on Team Diversity and Team Performance

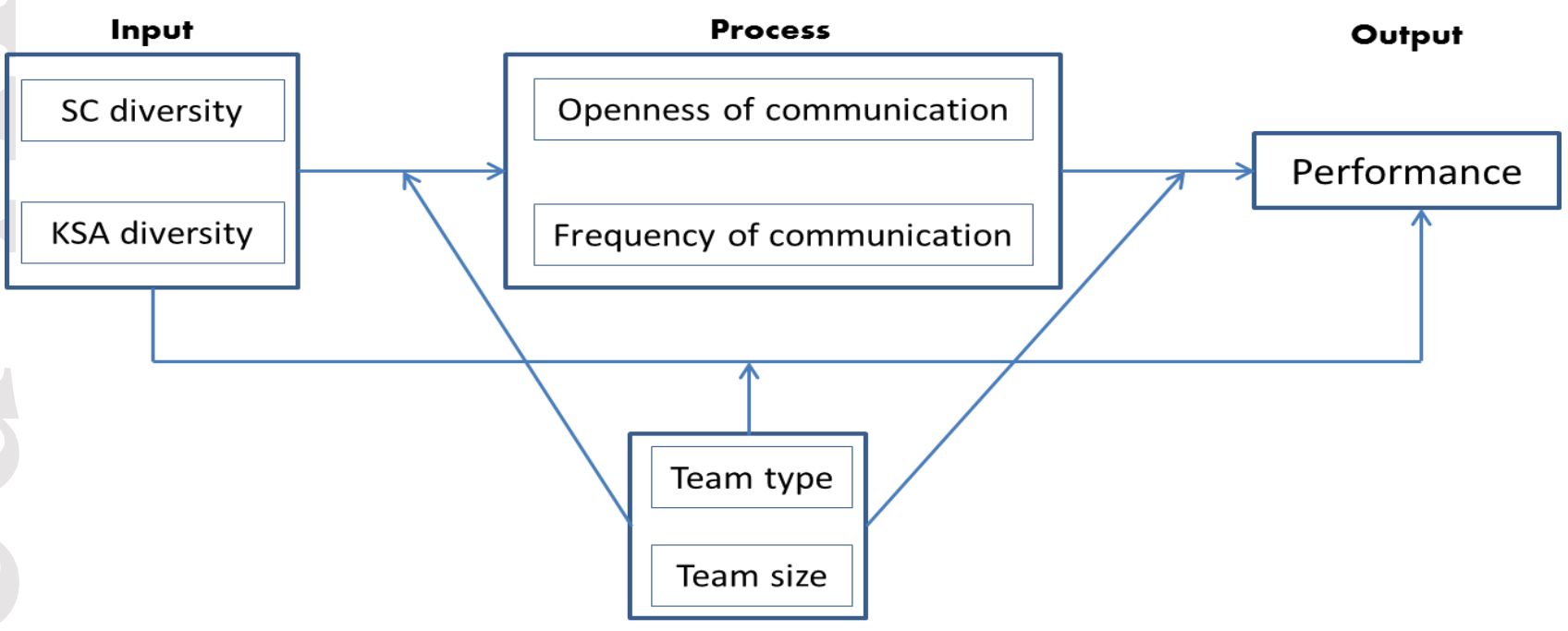

Moderators

This article is protected by copyright. All rights reserved. 
Table 1. Team Diversity, Openness of Communication and Frequency of Communication

\begin{tabular}{lcccccccccc}
\hline & $\mathbf{K}$ & $\mathbf{n}$ & $\mathbf{R m n W}$ & SDmW & VARSE\% & $\boldsymbol{\rho}$ & \multicolumn{1}{c}{ SD } & \multicolumn{2}{c}{ 95\%-CI } & VARA\% \\
\hline Openness of Communication & 25 & 1,402 & 0.119 & 0.150 & 0.781 & 0.129 & 0.076 & -0.017 & 0.280 & 0.784 \\
SC Differences & 16 & 880 & 0.123 & 0.123 & 1 & 0.131 & 0 & 0 & 0 & 1 \\
Internal Com. & 10 & 538 & 0.064 & 0.121 & 1 & 0.068 & 0 & 0 & 0 & 1 \\
KSA Differences & 9 & 522 & 0.111 & 0.187 & 0.488 & 0.135 & 0.150 & -0.159 & 0.430 & 0.492 \\
Internal Com. & 8 & 465 & 0.119 & 0.197 & 0.440 & 0.146 & 0.166 & -0.179 & 0.472 & 0.444 \\
Average ES & 8 & 436 & 0.075 & 0.141 & 0.932 & 0.085 & 0.040 & 0.006 & 0.163 & 0.932 \\
& & & & & & & & & \\
Frequency of Communication & 31 & 2,414 & 0.039 & 0.182 & 0.393 & 0.051 & 0.153 & -0.249 & 0.351 & -0.200 \\
SC Differences & 15 & 1,183 & -0.006 & 0.113 & 1 & -0.007 & 0 & 0 & 0 \\
Internal Com. & 13 & 819 & 0.013 & 0.122 & 1 & 0.013 & 0 & 0 & 0 \\
KSA Differences & 16 & 1,231 & 0.084 & 0.220 & 0.268 & 0.107 & 0.215 & -0.314 & 0.529 & 0.270 \\
Internal Com. & 8 & 646 & 0.042 & 0.222 & 0.254 & 0.049 & 0.225 & -0.393 & 0.492 & 0.255 \\
Average ES & 11 & 739 & 0.096 & 0.147 & 0.682 & 0.112 & 0.090 & -0.065 & 0.289 & 0.699 \\
\hline
\end{tabular}

Note: $\mathrm{K}=$ number of correlations; $\mathrm{n}=$ total sample size; $\mathrm{RmnW}=$ sample-weighted mean correlation; sample-weighted standard deviation of the SWMr; VARSE $\%=$ percentage of variance attributed to sampling error; $\rho=$ corrected population correlation; SD $\rho=$ standard deviation of the corrected population correlation; $95 \%-\mathrm{CI}=95 \%$ confidence interval; VAR A $\%=$ percentage of variance attributed to sampling error and artifact corrections. Com. is communication. Average ES is the average of the effect sizes from the same study.

This article is protected by copyright. All rights reserved. 
Table 2. Openness of Communication and Frequency of Communication and Team Performance

\begin{tabular}{|c|c|c|c|c|c|c|c|c|c|c|}
\hline & $\mathbf{K}$ & $\mathbf{n}$ & RmnW & SDmW & VARSE\% & $\boldsymbol{\rho}$ & SDp & \multicolumn{2}{|c|}{$95 \%$-CI } & VARA\% \\
\hline Openness of Communication & 19 & 842 & 0.309 & 0.188 & 0.536 & 0.348 & 0.145 & 0.064 & 0.633 & 0.550 \\
\hline Low Uncertainty & 9 & 475 & 0.354 & 0.173 & 0.491 & 0.395 & 0.139 & 0.121 & 0.668 & 0.505 \\
\hline High Uncertainty. & 10 & 367 & 0.250 & 0.189 & 0.689 & 0.289 & 0.121 & 0.050 & 0.527 & 0.695 \\
\hline Project Team & 5 & 153 & 0.350 & 0.126 & 1 & 0.424 & 0 & 0 & 0 & 1 \\
\hline Average ES & 12 & 582 & 0.336 & 0.187 & 0.472 & 0.375 & 0.153 & 0.074 & 0.675 & 0.486 \\
\hline Frequency of Communication & 51 & 3,807 & 0.174 & 0.164 & 0.474 & 0.199 & 0.135 & -0.065 & 0.464 & 0.486 \\
\hline Low Uncertainty & 30 & 1,886 & 0.151 & 0.176 & 0.498 & 0.172 & 0.141 & -0.105 & 0.448 & 0.510 \\
\hline High Uncertainty. & 21 & 1,921 & 0.197 & 0.148 & 0.466 & 0.226 & 0.123 & -0.015 & 0.468 & 0.473 \\
\hline Project Team & 31 & 1,888 & 0.122 & 0.190 & 0.450 & 0.146 & 0.159 & -0.166 & 0.458 & 0.451 \\
\hline Average ES & 16 & 1,177 & 0.153 & 0.139 & 0.681 & 0.171 & 0.087 & 0.000 & 0.342 & 0.689 \\
\hline
\end{tabular}

Note: $\mathrm{K}=$ number of correlations; $\mathrm{n}=$ total sample size; $\mathrm{RmnW}=$ sample-weighted mean correlation; sample-weighted standard deviation of the SWMr; VARSE \% = percentage of variance attributed to sampling error; $\rho=$ corrected population correlation; SD $\rho=$ standard deviation of the corrected population correlation; 95\%-CI $=95 \%$ confidence interval; VAR A $\%=$ percentage of variance attributed to sampling error and artifact corrections.

Com. is communication. Average ES is the average of the effect sizes from the same study.

This article is protected by copyright. All rights reserved. 
Table 3. Diversity, Communication and Team Performance

\begin{tabular}{|c|c|c|c|c|c|c|c|c|c|c|}
\hline & $\mathbf{K}$ & $\mathbf{n}$ & RmnW & SDmW & VARSE\% & $\boldsymbol{\rho}$ & SDp & \multicolumn{2}{|c|}{$95 \%-C I$} & VARA \% \\
\hline SC Differences & 23 & 1,130 & -0.022 & 0.125 & 1 & -0.024 & 0 & 0 & 0 & 1 \\
\hline Low Uncertainty & 4 & 390 & -0.046 & 0.118 & 0.742 & -0.046 & 0.063 & -0.169 & 0.078 & 0.745 \\
\hline High Uncertainty. & 19 & 740 & -0.010 & 0.126 & 1 & -0.010 & 0 & 0 & 0 & 1 \\
\hline Internal Communication & 19 & 777 & -0.054 & 0.127 & 1 & -0.056 & 0 & 0 & 0 & 1 \\
\hline Low Openness of Communication & 17 & 966 & -0.003 & 0.112 & 1 & -0.003 & 0 & 0 & 0 & 1 \\
\hline High Openness of Communication & 140 & 894 & -0.006 & 0.110 & 1 & -0.006 & 0 & 0 & 0 & 1 \\
\hline Frequency of Communication & 6 & 164 & -0.135 & 0.134 & 1 & -0.141 & 0 & 0 & 0 & 1 \\
\hline KSA Differences & 26 & 1,587 & 0.044 & 0.200 & 0.415 & 0.043 & 0.169 & -0.288 & 0.375 & 0.416 \\
\hline Low Uncertainty & 12 & 847 & 0.080 & 0.151 & 0.620 & 0.078 & 0.105 & -0.127 & 0.283 & 0.624 \\
\hline High Uncertainty. & 14 & 740 & 0.003 & 0.237 & 0.342 & 0.004 & 0.210 & -0.407 & 0.415 & 0.342 \\
\hline Internal Communication & 14 & 658. & 0.006 & 0.214 & 0.473 & -0.002 & 0.166 & -0.327 & 0.323 & 0.473 \\
\hline Openness of Communication & 15 & 1,073 & 0.060 & 0.207 & 0.329 & 0.066 & 0.035 & -0.302 & 0.435 & 0.330 \\
\hline High Openness of Communication & 11 & 873 & 0.088 & 0.212 & 0.281 & 0.095 & 0.201 & -0.299 & 0.489 & 0.332 \\
\hline Frequency of Communication & 11 & 514 & 0.011 & 0.181 & 0.671 & 0.013 & 0.013 & -0.210 & 0.236 & 0.671 \\
\hline High Frequency of Communication & 7 & 338 & 0.000 & 0.188 & 0.597 & -0.013 & 0.133 & -0.273 & 0.247 & 0.597 \\
\hline Average ES & 12 & 816 & 0.070 & 0.131 & 0.866 & 0.074 & 0.052 & -0.029 & 0.176 & 0.868 \\
\hline
\end{tabular}

Note: $\mathrm{K}=$ number of correlations; $\mathrm{n}=$ total sample size; $\mathrm{RmnW}=$ sample-weighted mean correlation; sample-weighted standard deviation of the SWMr; VARSE $\%=$ percentage of variance attributed to sampling error; $\rho=$ corrected population correlation; SD $\rho=$ standard deviation of the corrected population correlation; $95 \%-\mathrm{CI}=95 \%$ confidence interval; VAR A $\%=$ percentage of variance attributed to sampling error and artifact corrections.

Com. is communication. Average ES is the average of the effect sizes from the same study.

This article is protected by copyright. All rights reserved. 
Figure 2: Publication Bias

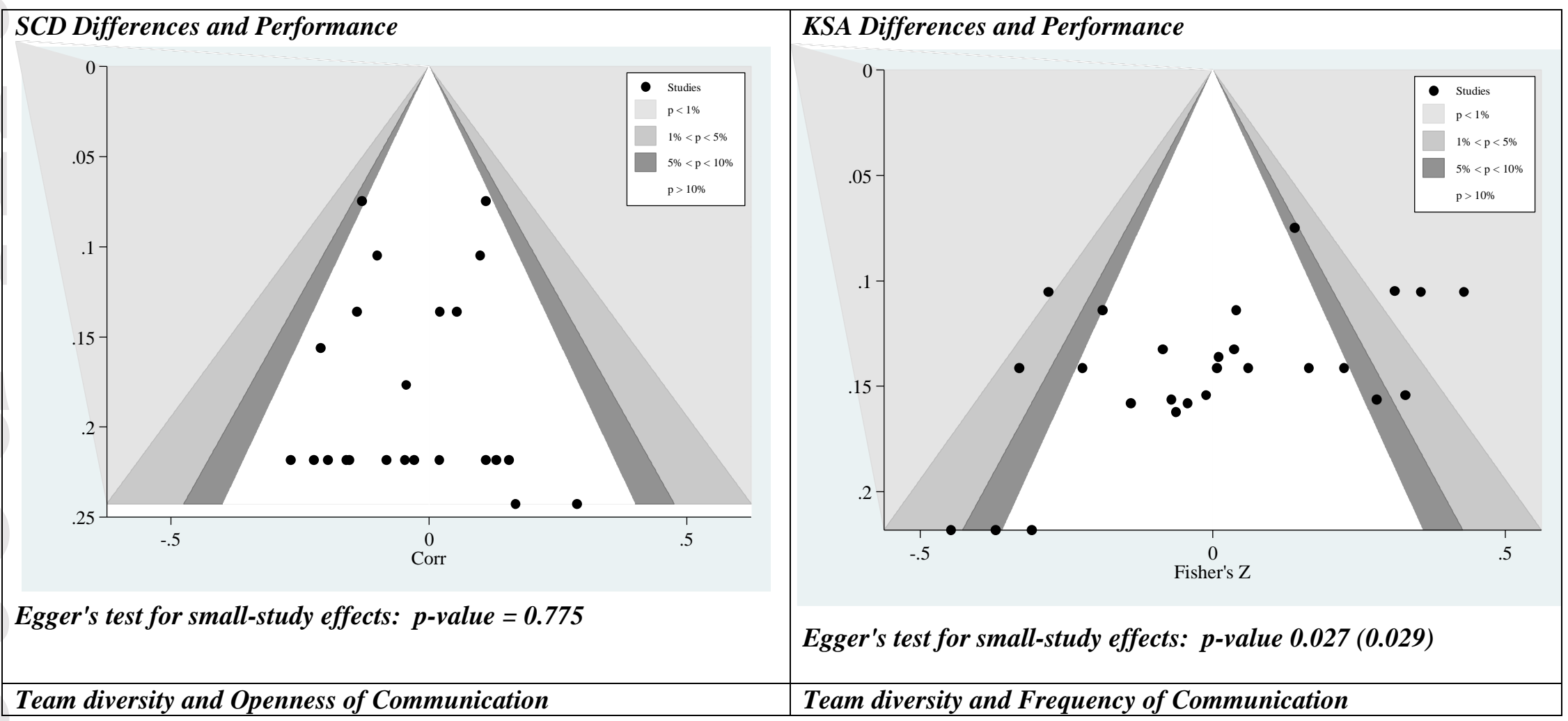

This article is protected by copyright. All rights reserved. 


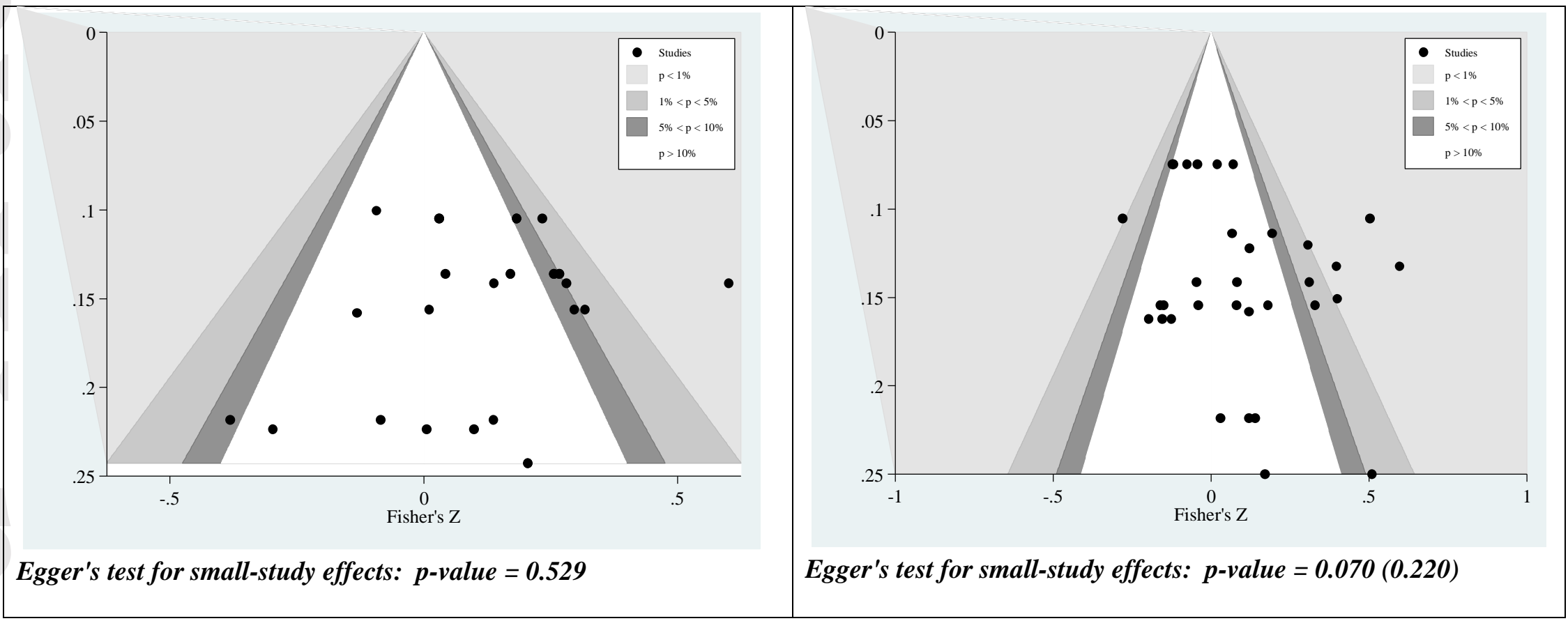

This article is protected by copyright. All rights reserved. 


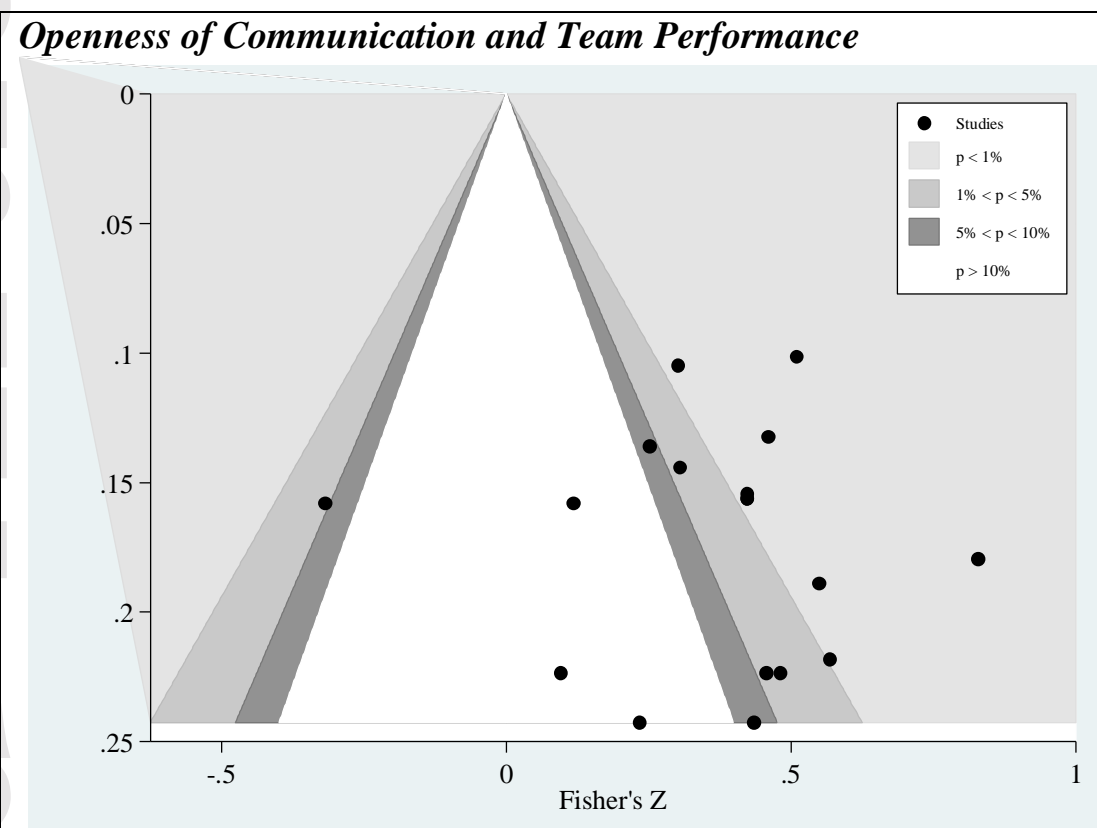

Egger's test for small-study effects: $p$-value $=0.824$

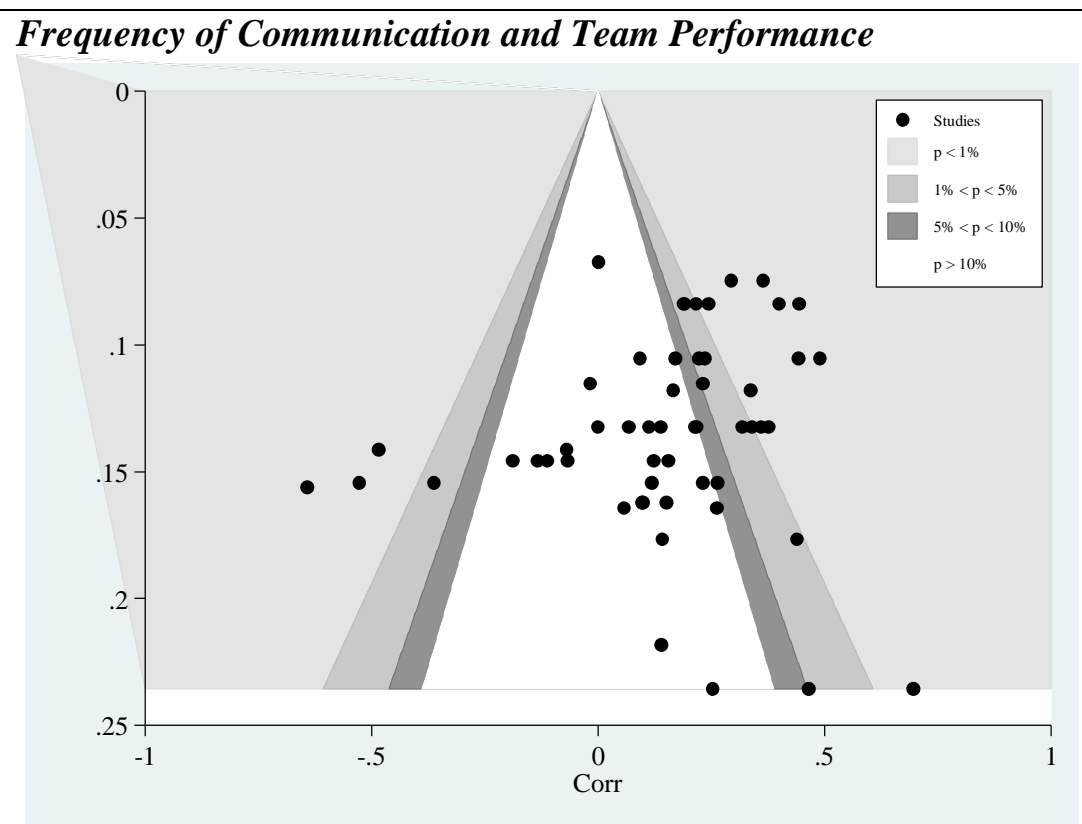

Egger's test for small-study effects: $p$-value $=0.049(0.474)$

Note: Figure 2 shows the plot of the inverse standard error (y-axis) versus the effect size (x-axis). The effect size is the Fisher-Z for the sampleweighted mean correlation corrected for the artifacts. We use the confunnel command available in Stata to get the funnel-plot. For Egger's test we use the metabias command. In parenthesis, it is reported the Egger's test after controlling for data-dependence issue, by averaging the correlations per study.

This article is protected by copyright. All rights reserved. 